\title{
PERÍODO DE INFECTIVIDADE DE ANIMAIS INOCULADOS EXPERIMENTALMENTE COM YERSINIA sp*
}

Beatriz Maria Machado de Medeiros**

Mario Tsunezi Shimizu***

Deise Pasetto Falcão**

\begin{abstract}
MEDEIROS, B.M.M. de et al. Período de infectividade de animais inoculados experimentalmente com Yersinia sp. Rev. Saúde públ., S. Paulo, 21: 261-4, 1987.

RESUMO: Lotes de camundongos suiços convencionais foram inoculados tanto por via intragástrica (IG) quanto por via intravenosa (IV) com Yersinia enterocolitica dos sorotipos 0:3, 0:8 e 0:9 e com amostras de yersinias atípicas. Foi mantido um lote de animais não inoculados como controle. Verificou-se qual o período de permanência dessas bactérias no intestino dos animais inoculados. Yersinia enterocolitica dos sorotipos 0:3, 0:8 e 0:9, considerados adaptados ao homem, permaneceram no intestino dos animais inoculados por um período muito maior do que as amostras de Yersinia não adaptadas, quer inoculadas por via intragástrica, quer por via intravenosa.
\end{abstract} logia.

UNITERMOS: Yersinia enterocolitica. Camundongos, microbiologia. Infecções por Yersinia, microbio-

\section{INTRODUÇÃO}

Infecções humanas por Yersinia enterocolitica, principalmente enterites, ocorrem com freqüência, sempre associadas a determinados sorotipos ${ }^{1,6,10}$.

A noção de adaptação de certas amostras de Yersinia a um ou vários hospedeiros é de grande importância no estudo desse grupo de microrganismos. Sabe-se que certas amostras têm um habitat preferencial ou um hospedeiro quase que exclusivo, no qual manifestarão seu poder patogênico ${ }^{7}$. Os biotipos 2 e 4 são adaptados ao homem, enquanto os outros biotipos e as yersinias atípicas não o são. Esses biotipos adaptados ao homem estão quase sempre associados aos sorotipos 0:3 e 0:9 e menos freqüentemente ao 0:8.

Uma série de trabalhos vêm sendo desenvolvidos em nosso laboratório, na tentativa de elucidar alguns aspectos ainda obscuros a respeito desses microrganismos. Um desses aspectos refere-se ao período de permanência de cepas de Yersinia consideradas adaptadas ao homem, no intestino de camundongos infectados experimentalmente. Em trabalho anterior ${ }^{4}$ esse animal mostrou-se um bom modelo nesse tipo de estudo.

Foram feitos alguns relatos sobre o período de eliminação de $Y$. enterocolitica em animais infectados experimentalmente com cepas de diferentes sorotipos, inoculados em diferentes espécies de animais por diferen- tes vias $2,5,8,9,11$, não existindo entretanto, dados a respeito, com amostras de yersinias atípicas.

Estudos realizados por Falcão e $\mathrm{col} .{ }^{4}$ mostram que amostras de Yersinia adaptadas ao homem, quando inoculadas por via intragástrica, têm a capacidade de invadir vários órgãos e tecidos, onde permanecem por períodos variáveis, proliferando ou não. Amostras não adaptadas não apresentam capacidade invasora.

O objetivo do presente trabalho foi o de infectar camundongos suiços convencionais com Yersinia enterocolitica dos sorotipos mais freqüentemente associados com doenças no homem, e com Y. frederiksenii, Y. kristensenii e $Y$. intermedia e verificar o periodo de permanência no intestino desses animais, tentando-se, assim, estabelecer o período de infectividade desses microrganismos.

\section{MATERIAL E MÉTODOS}

1. Animais de experimento: camundongos suiços, fêmeas, albinos, com 6 a 8 semanas de idade.

2. Amostras bacterianas: foram estudadas sete amostras de Yersinia, cujas características são apresentadas na Tabela 1.

* Trabalho financiado pelo Conselho Nacional de Desenvolvimento Científico e Tecnológico (CNPq), Processo n? 40.2822/81, e pela Comissão de Projetos Especiais da UNESP, Processo n? 3429/82.

** Departamento de Ciências Biológicas da Faculdade de Ciências Famacêuticas da Universidade Estadual Paulista "Júlio de Mesquita Filho" (UNESP) - Rua Expedicionários do Brasil, 1621 - 14800 - Araraquara, SP - Brasil.

*** Departamento de Patologia da Faculdade de Odontologia da Universidade Estadual Paulista "Júlio de Mesquita Filho" (UNESP)

- Av. Engenheiro Francisco José Longo, 777 - 12200 - São José dos Campos, SP - Brasil. 


\section{TABELA 1}

Características das amostras de Yersinia estudadas.

\begin{tabular}{llcccc}
\hline Amostra & Espécie & $\begin{array}{c}\text { Bio- } \\
\text { tipo }\end{array}$ & $\begin{array}{c}\text { Soro- } \\
\text { tipo }\end{array}$ & $\begin{array}{c}\text { Liso- } \\
\text { tipo }\end{array}$ & Origem \\
\hline FCF-59 & Y. enterocolitica & 4 & $0: 3$ & VIII & humana \\
IP-2707 & Y. enterocolitica & 2 & $0: 8$ & $\mathrm{X}_{\mathrm{z}}$ & humana \\
IP-373 & Y. enterocolitica & 2 & $0: 9$ & $\mathrm{X}_{\mathrm{z}}$ & humana \\
FCF-13 & Y. intermedia & & $0: 18$ & $\mathrm{X}_{\mathrm{z}}$ & leite crú \\
FCF-61 & Y. kristensenii & & $0: 9$ & $\mathrm{X}_{\mathrm{z}}$ & leite crú \\
IP-8180 & Y. frederiksenii & & $0: 16$ & $\mathrm{X}_{\mathrm{z}}$ & leite crú \\
\hline
\end{tabular}

3. Esquema de inoculação:

a) Via intragástrica: os camundongos foram inoculados com o auxílio de uma sonda de polivinil flexível, com $10^{7}$ a $10^{8}$ células de Yersinia do sorotipo correspondente.

b) Via intravenosa: os camundongos foram inoculados através de injeção na veia da cauda dos animais, com $10^{7}$ a $10^{9}$ células de Yersinia com exceção do sorotipo $0: 8$, cuja dose foi de apenas $10^{3}$ células por se tratar de uma dose sub-letal.

\section{Período de eliminação:}

Cada amostra foi inoculada em 2 lotes constituídos cada um por 60 camundongos, sendo os do primeiro lote inoculados por via intragástrica, os do segundo por via intravenosa; um terceiro lote de animais normais foi utilizado como controle.

Os camundongos foram observados por um período de 10 semanas e grupos de 5 sacrificados periodicamente: animais inoculados com $Y$. intermedia, $Y$. frederiksenii e $Y$. kristensenii após 6 horas, 1 dia, 3 dias e a seguir semanalmente; os inoculados com $Y$. enterocolitica dos sorotipos 0:3, 0:8 e 0:9 foram sacrificados semanalmente. De cada animal retirava-se cerca de $1 / 3$ do ceco o qual foi homogeneizado e diluído em caldo simples e semeado em Agar MacConkey. As placas foram incubadas a $25^{\circ} \mathrm{C}$ por $48 \mathrm{~h}$. As colônias suspeitas foram submetidas a caracterização sorológica. O caldo simples restante foi incubado a $4^{\circ} \mathrm{C}$ para enriquecimento. Nos casos de cultura negativa para Yersinia no primeiro isolamento, realizava-se semeadura a partir do caldo simples enriquecido a frio em placas de Agar MacConkey, semanalmente até o máximo de 21 dias. Essas placas foram incubadas a $25^{\circ} \mathrm{C}$ por $24-48 \mathrm{~h}$ e as colônias suspeitas submetidas à caracterização sorológica.

\section{RESULTADOS E DISCUSSÃO}

Os resultados do período de eliminação das yersinias, através das fezes dos animais infectados, por via intragástrica e intravenosa, encontram-se na Tabela 2 .

A Y. enterocolitica $0: 3$, considerada patogênica, inoculada nos animais por via intragástrica, numa dose de $1,2.10^{8}$ células, foi detectada no intestino até 35 dias após a inoculação. Quando inoculada por via venosa, na dose de $3,0.10^{8}$ células, foi eliminada pelas fezes durante 49 dias. Esses períodos são um pouco maiores do que os relatados na literatura. Assim, Alonso e col. ${ }^{2}$, trabalhando com o mesmo tipo de animais, mas inoculados por via IV com uma amostra do sorotipo 0:3, observaram um período de eliminação de mais de 14 dias. Pearson e col. ${ }^{9}$, trabalhando com a mesma amostra inoculada por via intraperitoneal, obtiveram um período de eliminação de apenas 20 dias. Ogata e col. ${ }^{8}$, trabalhando com coelhos albinos e camundongos "specific pathogen free" (ICR) inoculados por via IV e por via oral, observaram um período de eliminação de 21 a 28 dias, mais próximo ao encontrado na presente pesquisa.

A Y. enterocolitica do sorotipo 0:8, utilizada nestes experimentos é a amostra WA, isolada por Carter ${ }^{3}$, altamente patogênica para camundongo e para o homem. Nossos resultados mostram que os animais inoculados por via intragástrica, com uma dose de $4.10^{7}$ células, eliminaram a bactéria durante 63 dias. Pearson e col. ${ }^{9}$, utilizando camundongos "Porton white" inoculados com a mesma dose e pela mesma via, verificaram que os animais excretavam a amostra WA por um período

TABELA 2

Presença de $Y$. enterocolitica, $Y$. intermedia, $Y$. frederiksenii e $Y$. kristensenii no conteúdo cecal de grupos de 5 camundongos infectados experimentalmente por via intragástrica (IG) e por via intravenosa (IV)

\begin{tabular}{|c|c|c|c|c|c|c|c|c|c|c|c|c|c|}
\hline \multirow{2}{*}{$\begin{array}{l}\text { Período } \\
\text { após infecção }\end{array}$} & \multicolumn{2}{|c|}{ Y.e. 0:3 } & \multicolumn{2}{|c|}{ Y.e. $0: 8$} & \multicolumn{2}{|c|}{ Y.e. 0:9 } & $Y$. & intermedia & \multicolumn{2}{|c|}{ Y. frederiksenii } & \multicolumn{2}{|c|}{ Y. kristensenii } & \multirow{2}{*}{$\begin{array}{l}\text { Grupo } \\
\text { Controle }\end{array}$} \\
\hline & IG & IV & IG & IV & IG & IV & IG & IV & IG & IV & IG & IV & \\
\hline 6 horas & NT & NT & NT & NT & NT & NT & + & + & NT & NT & NT & - & - \\
\hline $1 \mathrm{dia}$ & NT & NT & NT & NT & NT & NT & + & + & + & + & - & - & - \\
\hline 3 dias & NT & NT & NT & NT & NT & NT & - & - & - & + & - & - & - \\
\hline 7 dias & + & + & - & + & + & + & - & - & - & + & - & - & - \\
\hline 14 dias & + & + & + & + & + & + & - & - & - & - & - & - & - \\
\hline 21 dias & + & + & + & + & + & + & - & - & - & - & - & - & - \\
\hline 28 dias & + & + & + & + & + & + & - & - & - & - & - & - & - \\
\hline 35 dias & + & + & + & + & + & + & - & - & - & - & - & - & - \\
\hline 42 dias & - & + & + & + & + & + & - & - & - & - & - & - & - \\
\hline 49 dias & - & + & + & NT & + & + & - & - & - & - & - & - & - \\
\hline 56 dias & - & - & - & NT & + & - & - & - & - & - & - & - & - \\
\hline 63 dias & - & - & + & NT & + & - & - & - & - & - & - & - & - \\
\hline 70 dias & - & - & - & NT & + & - & - & - & - & - & - & - & - \\
\hline
\end{tabular}

NT $=$ não testado

Y.e. = Yersinia enterocolitica 
de até 123 dias. De acordo com a Tabela 1, observa-se que quando os animais foram inoculados por via IV, numa dose de $1,5.10^{2}$ células, a bactéria foi encontrada nas fezes até $\mathbf{4 2}$ dias após a infecção, depois do que, os animais remanescentes morreram. Maruyama e col. ${ }^{5}$, inoculando cerca de $10^{6}-10^{8}$ de $Y$. enterocolitica 0:8 WA em camundongos, pela mesma via, recuperaram a bactéria até 61 dias após a inoculação.

Os animais inoculados por via IG, com $1,5.10^{7}$ células de $Y$. enterocolitica do sorotipo 0:9, excretaram a bactéria, durante todo o período de observação (70 dias) e os inoculados por via IV, com $8.10^{7}$ células, durante 49 dias. Estes resultados são semelhantes ao observado na literatura $5,9,11$.

Quanto aos resultados obtidos com as yersinias atípicas, consideradas não adaptadas ao homem e portanto não patogênicas, verificou-se que essas amostras são rapidamente eliminadas do intestino. Inoculando-se cerca de $5.10^{7}$ células de $Y$. intermedia por via $\mathrm{IG}$ e $1.10^{8}$ células por via IV, o período de permanência foi de 1 dia, em ambos os casos. Quando se inoculou $5.10^{8}$ células de $Y$. frederiksenii, por via IG, o microrganismo permaneceu no intestino também por 1 dia, enquanto que, quando inoculada por via IV $\left(1.10^{9}\right.$ células), per- maneceu nesse local por 7 dias. Os animais inoculados com $Y$. kristensenii não eliminaram bactérias em nenhum dos períodos estudados.

Os resultados obtidos, após inoculação intragástrica e intravenosa, mostram diferenças importantes de comportamento. O período de permanência no intestino dos animais de $Y$. enterocolitica dos sorotipos 0:3, 0:8 e 0:9, foi consideravelmente maior quando comparado com aquele apresentado pelas yersinias atípicas, que são tidas como não adaptadas ao homem, e que foram detectadas por um curto período de tempo.

Esses resultados mostram que o tempo de permanência de Yersinia no intestino dos camundongos, onde podem ou não se colonizar, é diretamente proporcional à sua capacidade de adaptação ao homem, consequentemente à sua provável capacidade de causar doenças, quer quando inoculadas por via intragástrica quer por via intravenosa.

Mostram também que o período de infectividade das yersinias causadoras de doença no homem, quando inoculadas em camundongos é bem mais longo que das consideradas como yersinias ambientais, tornando as primeiras mais patogênicas em decorrência do período maior que são eliminadas com as fezes.

\begin{abstract}
ME DE I ROS, B.M.M. de et al. [Period of infectivity of animals challenged by Yersinia sp]. Rev. Saúde públ., S. Paulo, 21: 261-4, 1987.

ABSTRACT: Conventional swiss mice were innoculated intragastrically (IG) and intravenously (IV) with Yersinia enterocolitica serotypes 0:3, 0:8 and 0:9 and with Yersinia enterocolitica like strains. A control animal group was not innoculated. The period that strains remained in the cecal content after the IG and IV challenge was determined. After IG and IV innoculation, Yersinia enterocolitica serotypes 0:3, 0:8 and 0:9, considered adapted to man, were isolated from the cecal content for a longer period than those considered nonadapted.
\end{abstract}

UNITERMS: Yersinia enterocolitica. Mice, microbiology. Yersinia, infections, microbiology.

\title{
REFERENCIAS BIBLIOGRÁFICAS
}

1. AHVONEN, P. Yersinia enterocolitica infections in Finland. In: International Symposium on Yersinia, Pasteurella and Francisella, Malmo, 1972. Proceedings. Basel, Karger, 1973. p. 133-4.

2. ALONSO, J.M.; MAZIGH, D.; BERCOVIER, H.; MOLLARET, H.H. Infection expérimentale de la souris par Yersinia enterocolitica (souche du chimiotype 4, du sérogroupe 0:3, du lysotype VIII): devenir de l'inoculum chez des souris athymiques on traitées par le cyclophosphamide. Ann. Microbiol., 129B: 27-36, 1978.

3. CARTER, P.B.; VARGA, C.F.; KEET, E.E. New strain of Yersinia enterocolitica pathogenic for rodents. Appl. Microbiol., 26: 1016-8, 1973.

4. FALCÃO, D.P.; SHIMIZU, M.T.; TRABULSI, L.R. Kinetics of infection induced by Yersinia. Curr. Microbiol., 11: 303-8, 1984.

5. MARUYAMA, T.; UNE, T.; ZEN-YOJI, H. - Observations on the correlation between pathogenicity and serovars of Yersinia enterocolitica by the assay applying cell culture system and experimental mouse infection. Contrib. Microbiol. Immunol., 5: 317-23, 1979.

6. MOLLARET, H.H.; BERCOVIER, H.; ALONSO, J.M. Summary of the data received at the WHO Reference Center for Yersinia enterocolitica. In: International Symposium on Yersinia, $3^{\text {rd }}$, Montreal, 1977. Yersinia enterocolitica: biology, epidemiology and pathology. Basel, Karger, 1979. p. 174-84. (Contribution to Microbiology and Immunology, v. 5).

7. MOLLARET, H.H. Curso "Yersinia". [Apresentado ao Congresso Latino-Americano de Microbiologia, 9?, São Paulo, 1983/Congresso Brasileiro de Microbiologia, 12\%, São Paulo, 1983].

8. OGATA, S.; KANAMORI, M.; MIYASHITA, K. Antige- 
nicity of protein and lipopolysaccharide from Yersinia enterocolitica. Contr. Microbiol. Immunol., 5: 64-72, 1979.

9. PEARSON, A.D.; RICCIARDI, I.D.; WRIGHT, D.H.; SUCKLING, W.G. An experimental study of the pathology and ecology of Yersinia enterocolitica infection in mice. Contr. Microbiol. Immunol., 5: 335-45, 1979.

10. RABSON, A.R. \& KOORNHOF, H.J. Yersinia enterocolitica infections in South Africa. In: International Sympo- sium on Yersinia, Pasteurella and Francisella, Malmo, 1972. Proceedings. Basel, Karger, 1973, p. 102-5.

11. UNE, T. Studies on the pathogenicity of Yersinia enterocolitica. I - Experimental infection in rabbits. Microbiol. Immunol., 21(7): 349.63, 1977.

Recebido para publicação em 20/10/1986

Reapresentado em 20/2/1987

Aprovado para publicação em 26/2/1987 